\title{
Promoting agricultural and rural modernization through application of information and communication technologies in China
}

\author{
Dongyu Qu ${ }^{1}$, Xiaobing Wang ${ }^{2 *}$, Chunpeng Kang ${ }^{2}$, Yang Liu ${ }^{2}$ \\ (1. Ministry of Agriculture and Rural Affairs, P. R. C, Beijing 100125, China; \\ 2. Information Center, Ministry of Agriculture and Rural Affairs, P. R. C, Beijing 100125, China)
}

\begin{abstract}
China has obtained remarkable major achievements of agricultural and rural development in the past five years, such as advance in agricultural supply-side structural reform, breakthroughs in rural reform, headway in urban-rural integration development, improvement in rural public services and social undertakings, progress in poverty alleviation, a new level in agricultural trade. Specifically speaking, China is witnessing the following development in Information and Communication Technology (ICT) application in rural areas: Internet infrastructure is strengthened; E-commerce in rural areas is thriving; rural information service is upgraded; A solid progress has been made in Agricultural Internet of Things and rapid deployment of big-data technology. This paper summarizes the experiences gained in the development of agricultural and rural informatization in China. Based on this review, some suggestions were presented: Firstly, improving policy systems through innovation; secondly, strengthening ICT infrastructure; thirdly, giving full play to the primary role of market; fourthly, carrying out pilot demonstration and trainings. At the same time, the problems faced by rural e-commerce development were also pointed out.
\end{abstract} Keywords: ICT application, agriculture and rural development, modernization, agricultural informatization, rural informatization, internet of things, e-commerce

DOI: $10.25165 /$ j.ijabe. 20181106.4228

Citation: Qu D Y, Wang X B, Kang C P, Liu Y. Promoting agricultural and rural modernization through application of information and communication technologies in China. Int J Agric \& Biol Eng, 2018; 11(6): 1-4.

\section{Introduction}

While adhering to the reform and opening-up policy, China is also committed to conserving our traditional farming culture. In this context, the Chinese Government has proposed the philosophy of innovative, coordinated, green, open and shared development, and pushes for innovation in its work related to agriculture, famers and rural areas (the "Three Rural-related Issues"). These efforts have brought a historic development and remarkable changes to agricultural sector and rural areas of China.

With a five-thousand-year history of farming, China has become one of the largest agricultural countries in the world. Smallholders play a vital role in conserving China's traditional farming culture, and they are still the basic units of agriculture and rural economy. Currently, rural China is inhabited by 258 million households with less than $2 \mathrm{hm}^{2}$ of farmland and 10.766 million households with land larger than this size ${ }^{[1]}$. There are only 366000 households whose holdings are larger than $13.3 \mathrm{hm}^{2}$. Even if China can reach a $70 \%$ of urbanization rate in the future, there will still be $400-500$ million people living in rural areas ${ }^{[1]}$. Therefore, a large country with a large population of smallholders will remain the underlying context of China's agricultural and rural

\section{Received date: 2018-05-20 Accepted date: 2018-10-25}

Biographies: Dongyu Qu, PhD, Research Professor, PhD Advisor, Vice Minister of MARA, research interests: potato breeding, agricultural economy, agricultural and rural informatization, Email: qudongyu@agri.gov.cn; Chunpeng Kang, $\mathrm{PhD}$, Associate Research Professor, research interests: agricultural and rural informatization, theory and practice, e-commerce, Email: cpkang@agri.gov.cn; Yang Liu, Engineer, research interests: agricultural and rural informatization and information service, Email: liuyang@agri.gov.cn.

*Corresponding author: Xiaobing Wang, Director of Information Center of MARA, research interests: agricultural marketization and informatization. Email: wangxb@agri.gov.cn. modernization. Historically, agriculture and rural areas have always been the main concern of the Chinese people. The present Chinese Government, which places on top of its agenda the work related to "the Three Rural Issues", has pledged to promote balanced progress in the reform and development of urban and rural areas. Our efforts have principally focused on agriculture and rural economy, and our achievements have been remarkable. The most notable one is to have fed $20 \%$ of the world's population with only $9 \%$ of cultivated land and $6.4 \%$ of freshwater resource on the Earth. More specifically, China's major achievements of agricultural and rural development in the past five years can be summarized as follows:

\subsection{Advance in agricultural supply-side structural reform}

China's annual grain production has exceeded 600 million $\mathrm{t}$ for 5 years in a row, and reached 618 million $\mathrm{t}$ (400 kg per capita) in $2017^{[2]}$. The supply of major agricultural products has remained abundant, with an increasing share of high-quality green products. Meanwhile, $66 \%$ of the plowing, sowing and harvesting of main crops has been mechanized ${ }^{[3]}$; the area of protected agriculture has surpassed 2083 thousand hectares ${ }^{[4]}$; and the contribution of science and technology to agricultural growth has risen to $57.5 \%{ }^{[3]}$. There are over three million new agribusiness entities including farmers cooperatives and family farms, involving more than 14 million new-type professional farmers.

\subsection{Breakthroughs in rural reform}

Having abolished the state stockpiling practice for cotton, soybean, rapeseed, sugar and maize, China has adopted a market-based price formation mechanism for agricultural produce. Regarding its rural land system, China has been advancing the reform to separate rights on ownership, contracting and management of land owned collectively by farmers, with a view to protecting ownership rights, stabilizing contracts and liberalizing the transfer of management rights. The rural land registration and 
certification progress is moving forward and has already covered $80 \%$ of contracted farmland. Many new industries and business models in recreational agriculture, rural e-commerce and rural tourism are flourishing, making rural areas popular destinations for business start-ups and investments.

\subsection{Headway in urban-rural integrated development}

Rural income has grown faster than urban income for years. Each year, Chinese farmers now earn over 5515 Yuan RMB more than they did 5 years ago. In 2017, their per capita disposable income reached 13432 Yuan RMB (about 2100 USD), bringing the urban-rural income gap down to 2.70:1. About a quarter of rural households have their own cars and a third have computers. A total of 660 million cellphones are used by farmers. With the improvement in rural living conditions, the Engel's Coefficient for rural residents has fallen from $39.3 \%$ in 2012 to $31.2 \%$ in 2017 . In the past 5 years, over 80 million Chinese farmers have become urban residents, pushing China's urbanization rate up to $58.52 \%$ in 2017 (less than 581 million live in rural areas for over 6 months

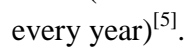

\subsection{Improvement in rural public services and social undertakings}

Comprehensive improvement has been made in rural infrastructures and living environment. Over the past five years, China has built roadways of 1.275 million $\mathrm{km}$ in rural areas (a third of the national total mileage), provided clean tap water for 250 million more rural residents (a total coverage of 90\%), and renovated over 15 million dilapidated houses in rural areas. In addition, China has started to unify pension schemes for rural and non-working urban residents. The serious disease insurance system which was established in rural areas years ago now covers all rural population. Social security for farmers has been put in place even if the level is not so high as expected.

\subsection{Progress in poverty alleviation}

Consistent efforts have been made to alleviate poverty through the development of local industries, education and healthcare, and the development and conservation of local ecological resources. The targeted poverty alleviation strategy has paid off. Over the past 5 years, a total of 68 million people have been lifted out of poverty, and the poverty headcount ratio has dropped from $10.2 \%$ to $3.1 \%{ }^{[6]}$, based on the poverty line of 2300 Yuan RMB per person per year (or 1 USD per person per day) in 2011 purchasing power parity terms.

\subsection{New high in agricultural trade}

In 2017, China's agricultural trade value registered 201.39 billion USD, including 75.53 billion USD in exports and 125.86 billion USD in imports, up by $9.1 \%, 3.5 \%$ and $12.8 \%$ respectively year on year. Last year, China's agricultural trade deficit increased by $30.4 \%$ to 50.33 billion $\mathrm{USD}^{[7]}$. By now, China has become the second largest trading country of agricultural products and one of the most open markets in the world.

In spite of these achievements, China is still a developing country with weak foundation and inadequate development. Agriculture, rural areas and farmers are still the most vulnerable parts in economic and social development. Slow agricultural and rural development holds back the process of modernization. Therefore, it is imperative to implement the Rural Revitalization Strategy.

\section{Progress in ICT application in agriculture and rural areas}

The historical achievements China has made in its agriculture and rural development are propelled by three engines: policy, technology, and investment \& market. ICT innovation, in particular, has made a significant contribution. ICT connects people, business and industries, bridges rural production with urban consumption, links smallholders with the market and modern agriculture, and integrates agriculture, rural areas and farmers. It has enhanced agricultural supply chain, industrial chain and value chain through the development of data chain. In recent years, China has seized the opportunity presented by e-commerce to integrate ICT, including the mobile internet, big data and the Internet of Things (IoT), with agricultural and rural development. This move has effectively facilitated the transformation of agriculture and improvement in rural living and working conditions. More specifically, China is witnessing the following development in ICT application in rural areas:

\subsection{Strengthened internet infrastructure}

China has kept improving rural internet infrastructure through the building of internet highway that covers all rural areas. As of December 2017, broadband has reached more than $96 \%$ of villages and over $90 \%$ of poor villages, $35.4 \%$ (209 million) of the total rural population are internet users ${ }^{[8]}$, and $25.1 \%$ of villages have built e-commerce distribution sites ${ }^{[9]}$. Meanwhile, the Beidou Navigation Satellite System has been used in key agricultural sectors, contributing to the integrated space-air-land system of agricultural data.

\subsection{Thriving e-commerce in rural areas}

The recent few years have seen an e-commerce boom across China, which enables the flow of manufactured goods to rural areas and farm produce to urban areas. In 2017, the online retail sales from rural areas stood at 1.25 trillion Yuan RMB, up by $39.1 \%$ year on year, among which online sales of farm produce was nearly 300 billion Yuan RMB and continues to grow at a high speed ${ }^{[10]}$. Rural e-commerce should be market-based and develop under the guidance of government to benefit farmers. To this end, China has established various models of e-commerce, such as "platform + self-run operation", "platform + settled-in merchants", "platform + brand marketing", and the whole value chain operation. E-commerce is playing a leading role in poverty alleviation. The Information Center of MARA conducted a survey across 592 poor counties and found that, thanks to e-commerce, local industries have developed rapidly and lifted 3.42 million people out of poverty, accounting for $15.7 \%$ of the total poverty reduction outcome in these counties ${ }^{[11]}$.

Here, we would like to share some local cases with you. Longnan is a city located in the mountainous area of Gansu Province in the Northwest of China. Among its 2.874 million people, 2.022 million are rural residents, and according to statistics, 1.305 million lived below the poverty line in 2011. The city is remote from the market, yet the improvement of local ICT infrastructure gives all poor villages under its administration connection to the internet. Through the "e-commerce + farmer" assistance model, a local farmer could sell an egg for 2 Yuan RMB and a kilogram of homemade honey for 90 Yuan RMB online, much higher than the previous offline prices of 0.5 Yuan RMB and 30 Yuan RMB respectively. On average, each year a farmer can earn 620 Yuan RMB more than before, thanks to the e-commerce model.

Guizhou Province is one of the poorest provinces in China. To reduce poverty, the province has used e-commerce to manage local ecological, agricultural and tourism resources and sell local products online. Efforts are made both online and offline: online 
pavilions for local products, online shops and WeChat shops; and offline county-level public service centers, logistic centers and rural service stations. In the past two years, e-commerce and big data technology have made great contribution to poverty reduction in the province and lifted over 1.2 million people out of poverty annually.

\subsection{Upgraded rural information service}

First, the website of the Ministry of Agriculture and Rural Affairs provides farmers and market entities with information on policies, market, technology and administrative approval, etc. It had 2.07 billion visits in 2017, ranking top among websites of Chinese governmental agencies. Second, the national "12316" hotline service offers free consultation to farmers for more than 100 million times per year, and connects farmers to experts, markets and governments. Third, the rural information service program carried out in 10 provinces has witnessed the establishment of 169000 information stations in administrative villages. These stations have provided convenience service for 233 million times and public service for 79.6 million times. The program is expected to cover $80 \%$ of all 600000 administrative villages by 2020. Fourth, the China Agricultural Outlook Conference that has been held for 5 successive years since 2014, provides forecasts on the market supply and demand of 18 major agricultural produce including grain, cotton, oil and sugar in the coming 10 years, based on a comprehensive analysis of macro economy, agricultural policies, climate conditions, technology innovation, resource endowments and market information, so as to provide guidance on production planning. The China International Agricultural Trade Fair has been held for 15 successive years and the First China International Import Expo was successfully held in Shanghai on November 5-10, 2018. China's market presents great opportunities to the world. All countries are welcome to board China's train of development.

\subsection{Solid progress in Agricultural Internet of Things}

In recent years, China has taken the R\&D and application of IoT as an important measure to reduce cost and improve efficiency in agriculture. The technology has been rapidly rolled out in protected agriculture, field cropping, scaled-up livestock, poultry and aquaculture production, and quality and safety traceability, generating notable economic, social and ecological benefits. In the project areas of the cotton-growing region of Xinjiang Uyghur Autonomous Region, IoT has improved fertilizer efficiency by $20 \%$, land use rate by $8 \%$, and overall benefits per hectare by 3150 Yuan RMB; and in Wuxi of Jiangsu Province, IoT has lifted aquaculture output per unit area up by $10 \%$, reduced power bills by 1200 Yuan $\mathrm{RMB} / \mathrm{hm}^{2}$, and secured income growth by 15 000-19 500 Yuan RMB/hm². It is foreseeable that the upcoming commercialization of 5G technology and NB-IoT will further speed up IoT application in agriculture.

\subsection{Rapid deployment of big-data technology}

In this area, China is pressing ahead with two major tasks: First, integration of administrative information to develop a catalogue of information resources on agriculture and rural areas, and a data-sharing platform that brings together data from all agricultural agencies, paving way for open access to public data and application of big data in agriculture and rural areas ${ }^{[11]}$. Second, pilot schemes for big data application. Following the guideline of whole-chain application for selected products, agriculture authorities, businesses, research institutes and colleges in major-producing regions are working together to roll out big-data pilot programs on apple, swine and tea, etc. The purpose is to capitalize on big data to address market price volatility, reduce losses caused by meteorological disasters and pests and diseases, advance financial service including insurance and futures, and promote high-quality development of agriculture ${ }^{[12]}$.

\section{Experience in ICT application on agriculture and rural areas}

The development of ICT presents remarkable opportunities for the whole world. Since the Eighteenth CPC National Congress, guided by President Xi Jinping's Thought on Socialism with Chinese Characteristics for a New Era, China has pursued the balanced development of new industrialization, ICT application, urbanization, and agricultural modernization, and prioritized ICT application in agricultural and rural modernization. China will improve "roof design" and take holistic measures to integrate ICT with the development of rural areas, agriculture and farmers for smart production, internet-based operation, digitalized management and online service.

\subsection{Improving policy systems through innovation}

In recent years, the Chinese Government has unveiled the "Internet Plus" action plan in keeping up with the trend of ICT revolution. President Xi Jinping has underlined the need to make accessible, affordable and high-quality information service universally available to our people, and to advance agricultural modernization by developing smart production and internet-based operation. It is also important to leverage ICT in targeted poverty alleviation so that more poor people can have access to the internet. Agricultural products can be sold out of villages through e-commerce, and children in remote regions can access high-quality education. To this end, the Ministry of Agriculture and Rural Affairs has laid out a series of policies to provide an enabling environment for accelerating ICT application in agriculture and rural areas, including The ICT Application Plan for Agriculture and Rural Areas during the Thirteenth Five-Year Period, The Three-Year Action Plan on "Internet Plus" Modern Agriculture, The Action Plan on E-commerce, and The Opinions on Implementing Big Data Application in Agriculture and Rural Areas.

\subsection{Strengthening ICT infrastructure}

In recent years, China has shored up weak links in rural ICT infrastructure, and continued to build broadband connections in rural areas and implement policies on facilitating faster and more affordable internet connection. The ICT capacity in rural areas has thereby greatly improved. Since 2014, China has conducted pilot programs in 116 counties to deploy ICT in rural households, which were expanded to 10 provinces in 2017. Such efforts have connected rural villages to the world. Henan Province is a big agricultural producer with a larger population and more administrative villages than any other provinces in China. In 2017, with 160 million Yuan RMB of financial subsidies from the central government, 800 million Yuan RMB from local governments and 150 million Yuan RMB of self-financing from telecom carriers, 38700 information centers were built and put into use in $80 \%$ of administrative villages in the province, providing public service, convenient service, e-commerce and training service to rural households. China has conducted rural e-commerce projects to increase support for poverty-stricken villages, mainly through building service systems, such as county-level e-commerce public service centers and village-level e-commerce service stations. Currently, we have built 756 demonstration counties in this regard, among which 498 are state-level poverty-stricken 
villages, accounting for $60 \%$ of the total.

\subsection{Giving full play to the primary role of market}

In recent years, China has enabled the market to play a decisive role in resources allocation and improved the functions of the government. Since agriculture and rural areas are fragile in nature, China has promulgated a series of supportive policies concerning investment, taxation, land and power supply, covering capital, return migrants' application of ICT and innovation and entrepreneurship in agriculture and rural areas.

These efforts have greatly motivated market entities to develop new industries and business models in rural areas. The number of agricultural internet enterprises is increasing. Large internet companies have started to explore the rural market, and traditional agricultural enterprises have embraced digital operation, forming a trend of innovation and entrepreneurship in rural areas. Currently, over 7.4 million people have started up their own business in rural areas, and most of them have applied ICT. Enterprises such as Alibaba, JD.com, Suning Commerce and China Post have started to explore e-commerce in rural areas by establishing poverty alleviation channels and providing new distribution channels for agricultural products, especially featured products from poverty-stricken areas. These measures have played an important role in lifting farmers out of poverty and increasing their income.

\subsection{Carrying out pilot demonstration and trainings}

China's agricultural reform often starts with a pilot program before full-scale implementation. This method is also adopted while introducing ICT to agriculture and rural areas. China has ensured that farmers play the principal role both in introducing ICT to villages and households, and in applying IoT and big data technology. Through demonstration projects, farmers are witnessing increase in their income, and become interested in using ICT to expand production and improve their living conditions. Smartphones have become a useful tool for farmers to search information, conduct online marketing, obtain service and bring convenience to life. Since 2015, skills trainings on mobile APP have been rolled out among rural residents. China will focus more on e-commerce of agricultural products to ensure the trainings are more targeted and on time. Farmers are encouraged to vote for their favorite mobile APPs. In the future, a smartphone will be the only thing required to manage agricultural production. Farmers can complete their work with a simple slide on the phone.

The development of rural e-commerce in China can provide reference to other developing countries. However, there are also challenges that constrain the high-quality development of this sector. Uneven regional development has resulted in a wide digital gap between East and West China, and between urban and rural areas; the online selling of farm produce grows slowly, and is mainly confined to primary products and price competition, with less progress in brand building and standardized operation; supporting systems are underdeveloped, particularly regarding post-harvest grading, packaging, distribution and cold-chain logistics; and, lack of human resource in rural areas, with much to be improved to attract and retain e-commerce talents ${ }^{[14]}$.

\section{China's development brings opportunities to the world}

The Rural Revitalization Strategy proposed by the $19^{\text {th }}$ CPC
National Congress is the foothold for addressing the "Three Rural-related Issues". China will seize the historical opportunity of ICT revolution to develop digital agriculture, build smart villages and achieve high-quality development of agriculture. ICT will be integrated with agricultural production, innovation of rural business models, agricultural product quality and safety control, and trainings of professional farmers. A strengthened digital economy in agriculture and rural areas will provide powerful support for the successful implementation of rural revitalization strategy.

While making its agriculture more digitalized, internet-driven and smart, China welcomes other countries to get on-board the fast train of internet and digital economy, and is ready to share our experience with other countries all over the world, especially developing countries. As China's economy grows, the purchasing power of Chinese consumers will increase rapidly amid a growing middle-income group. It is estimated that China's middle-income class (with an annual income of 3650-36 500 USD) will exceed 400 million people by the end of 2020, and will reach 600 million by 2030 . This provides a strong impetus for China to develop premium agricultural products and creates a large market for world agricultural products.

In the age of the internet, data flows will inevitably lead to the integrated development of technology, capital, human resource and material flows. Economic globalization and trade liberalization will not reverse simply because of a handful of people. China will only become more and more open. China's rural revitalization strategy will and must be implemented.

\section{[References]}

[1] Ministry of agriculture: China rural management statistics annual report, 2017, pp23. (in Chinese)

[2] National bureau of statistics: National bureau of statistics announcement on food production in 2017, http://www.stats.gov.cn/tjsj/zxfb/201712/ t20171208_1561546.html. (in Chinese)

[3] China agricultural and rural science and technology development report (2012-2017), 2018. (in Chinese)

[4] Report of agricultural mechanization management department of the ministry of agriculture and rural affairs, 2018. (in Chinese)

[5] National bureau of statistics: Statistical communique of the People's Republic of China on 2017 national economic and social development, http://www.stats.gov.cn/tjsj/zxfb/201802/t20180228_1585631.html.

[6] Report on the work of the government, 2018. (in Chinese)

[7] Department of international cooperation, ministry of agriculture: China's agricultural products import and export from January to December 2017, http://www.moa.gov.cn/ztzl/nybrl/rlxx/201801/t20180131_6136047.htm. (in Chinese)

[8] CNNIC: Statistical report on the development of China's internet (41st). 2018-1-3. (in Chinese)

[9] The main data bulletin of the third national agricultural census (No.3), http://www.stats.gov.cn/tjsj/tjgb/nypcgb/qgnypcgb/201712/t20171215_156 3589.html. (in Chinese)

[10] Ministry of commerce: 2017 China e-commerce development report,pp3

[11] Information center of ministry of agriculture: "Internet +" industry poverty alleviation report, 2017. (in Chinese)

[12] Wang X B, Kang C P. Focus on the promotion of agricultural big data development and application. Economic Daily, 2018-01-11. (in Chinese)

[13] Kang C P. The agricultural and rural digital economy should be cultivated. Economic Daily, 2018-07-26. (in Chinese)

[14] Kang C P. The development situation and trend of rural e-commerce in China. Farmer Daily, 2018-05-29. (in Chinese) 